Journal of the Magnetics Society of Japan Vol. 15 Supplement, No. S2 (1991)

(C) 1991 by The Magnetics Society of Japan

\title{
THEORETICAL ANALYSES OF READBACK WAVEFORM OF ISOLATED PERPENDICULAR MAGNETIZATION FOR DOUBLE - LAYER - MEDIUM WITH RING-TYPE HEAD
}

\section{Shenghua Zhang and Xiandeng Pei}

Department of Computer Engineering, Huazhong University of Science and Technology, Wuhan, Hubei, P. R. CHINA

Abstracts - - - There are two possible arrangements of the ring - type head and medium in a perpendicular recording system: (1) A ring-type head and a single-layer-medium. (2) A ring-type head and a double-layer-medium. The arrangement (2) is considered here. The readback process of isolated perpendicular magnetization for double-layer-medium with a ring - type head is discussed by reciprocity theorem. In the calculation process, the effect of self-demagnetizing field in medium is neglected. The interaction between the head and the high permeability layer in a double-layer-medium is analysed. The soft magnetic underlayer acts as an image plane for the ring - type head. Because of the interaction, the effective component of the recording field increases. The calculation of readback voltage indicates that the readback voltage is stronger than that of single-layer-medium. The effects of ring-type head permeability $\mu$ and recording bit length $2 \mathrm{~L}$ on readback voltage are also analysed here.

\section{INTRODUCTION}

Perpendicular magnetic recording has been shown to be capable of achieving high recording densities [1]. Initially, R. F. sputtered $C_{o}-C_{r}$ film was used as anisotropic medium. Subsequently, a composite anisotropic medium consisting of a $\mathrm{F}_{\mathrm{e}}-\mathrm{N}_{\mathrm{i}}$ soft magnetic film and a $\mathrm{C}_{\mathrm{o}}-\mathrm{C}_{\mathrm{r}}$ perpendicular anisotropic film has been used [2]. Ring-type heads have been used as read heads in perpendicular recording with double-layer media [3]. The presence of the image plane can significantly alter the magnetic field distribution for a ring - type head. The readback voltage is calculated by reciprocity theorem. Results of the calculation are presented and compared with those of a ring-type head without an image plane. The results of theoretical calculation are helping to supply the optimization design of perpendicular magnetic recording system with theoretical bases.

\section{CALCULATION OF THE RING - TYPE HEAD FIELD}

The field produced by actual recording heads is very difficult to calculate without a number of simplifying assumptions. As a result, the following assumptions are used.

a. The charge density of the pole pieces in the head gap is $\pm I_{r}$. The other positions of the ring type head have no charge.

b. The head is assumed to have infinite pole 
tip lengths.

c. The permeability of the head core is assumed to be $\mu$.

d. The soft magnetic underlayer is assumed to have infinite permeability.

e. Both the medium and the air have permeability $\mu_{0}$.

f. Geometry and coordinate system used for theoretical analysis is shown in Fig. 1.

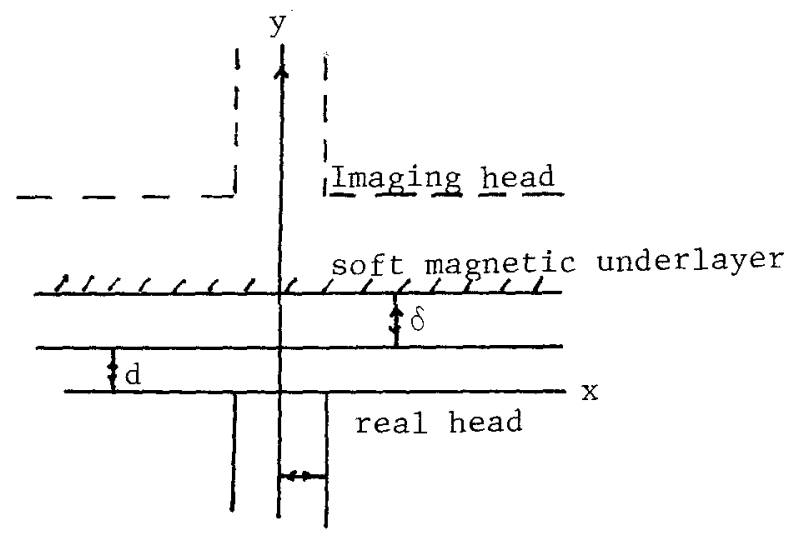

$\mathrm{g} / 2$

Figure. 1. Geometry and coordinate system used for theoretical analysis.

The real head field is [4]:

$\mathrm{H}_{y \mathrm{R}}=\frac{\mathrm{I}_{\mathrm{r}}}{4 \pi \mu_{0}} \ln \frac{\left(\mathrm{x}_{0}+\mathrm{g} / 2\right)^{2}+\mathrm{y}_{0}^{2}}{\left(\mathrm{x}_{0}-\mathrm{g} / 2\right)^{2}+\mathrm{y}_{0}^{2}}$

According to the imaging principle, the fringe field of the imaging head is:

$$
\begin{gathered}
\mathrm{H}_{\mathrm{yl}}=\frac{-1}{4 \pi \mu_{0}} \int_{2(\mathrm{~d}+\delta)=\mathrm{y}}^{\infty} \mathrm{dy} \int_{-\infty}^{\infty} \\
+\mathrm{I}_{\mathrm{r}}\left(\frac{\mu-\mu_{0}}{\mu+\mu_{0}}\right)\left(-\mathrm{y}_{0}+\mathrm{y}\right) \\
\left\{\frac{-\mathrm{I}}{\left[\left(\mathrm{x}_{0}+\mathrm{g} / 2\right)^{2}+\left(\mathrm{y}_{0}-\mathrm{y}\right)^{2}+\left(\mathrm{z}_{0}-\mathrm{z}\right)^{2}\right]^{3 / 2}}\right)\left(-\mathrm{y}_{0}+\mathrm{y}\right) \\
\left.+\frac{-\mu_{0}}{\left[\left(\mathrm{x}_{0}-\mathrm{g} / 2\right)^{2}+\left(\mathrm{y}_{0}-\mathrm{y}\right)^{2}+\left(\mathrm{z}_{0}-\mathrm{z}\right)^{2}\right]^{3} / 2}\right\} \mathrm{dz}
\end{gathered}
$$

Integration gives:

$$
\mathrm{H}_{\mathrm{yl}}=\frac{-\mathrm{I}_{\mathrm{r}}\left(\mu-\mu_{0}\right)}{4 \pi \mu_{0}\left(\mu+\mu_{0}\right)} \quad \text { ln } \quad \begin{aligned}
& \mathrm{e}(\overline{\mathrm{X}})=\mathrm{e}_{\mathrm{R}}(\overline{\mathrm{X}})+\mathrm{e}_{\mathrm{I}}(\overline{\mathrm{X}}) \\
& \text { Integration gives: }
\end{aligned}
$$
layer. is :

$\mathrm{H}_{\mathrm{y}}=\mathrm{H}_{\mathrm{y1}}+\mathrm{H}_{\mathrm{yR}}$ LAR MAGNETIZATION the function:

Where ring-type head is:

$\mathrm{H}_{\mathrm{y}} \mathrm{dy}_{0}$

The readback voltage is :

$e(\bar{X})=-\alpha N V \cdot \frac{\partial \varphi(\bar{X})}{\partial \bar{X}}$ ing (6) for $\varphi(\bar{X})$ in (7) give:

$\mathrm{H}_{\mathrm{yl}}$ in (3) is the increase part of fringe field resulted from the presence of soft magnetic under-

The effective fringe field of the ring - type head in the presence of a soft magnetic underlayer

CALCULATION OF READBACK VOLTAGE FOR AN ISOLATED STEP PERPENDICU-

It is assumed that the magnetization follows

$$
\begin{aligned}
& M_{x}(x, y, z)=0 \\
& M_{y}(x, y, z)=M_{r} \operatorname{Sign}\left(x_{0}-\bar{X}\right) \\
& M_{z}(x, y, z)=0
\end{aligned}
$$

$$
\operatorname{Sign}\left(\mathrm{x}_{0}-\overline{\mathrm{X}}\right)=\left\{\begin{array}{cc}
1 & \mathrm{x}_{0}>\bar{X} \\
-1 & \mathrm{x}_{0}<\overline{\mathrm{X}}
\end{array}\right.
$$

The magnetic track width is assumed to be $\mathrm{W}$. Hence, the total flux which enters the coils of the

$$
\varphi(\overline{\mathrm{X}})=\mu_{0} \mathrm{~W} \int_{-\infty}^{\infty} \mathrm{dx} \mathrm{x}_{0} \int_{\mathrm{d}=\mathrm{y}_{0}}^{\mathrm{d}} \mathrm{M}_{\mathrm{r}} \operatorname{Sign}\left(\mathrm{x}_{0}-\overline{\mathrm{X}}\right) \cdot
$$

Substituting (4) for $\mathrm{Hy}$ in (6) and substitut- 
$\mathrm{e}_{\mathrm{R}}(\overline{\mathrm{X}})=\frac{-\alpha N V W M_{\mathrm{r}} \mathrm{I}_{\mathrm{r}}}{2 \pi}\{(\mathrm{d}+\delta) \ln$ $\frac{(\bar{X}-g / 2)^{2}+(d+\delta)^{2}}{(\bar{x}+g / 2)^{2}+(d+\delta)^{2}}+d \cdot \ln \frac{(\bar{X}+g / 2)^{2}+d^{2}}{(\bar{X}-g / 2)^{2}+d^{2}}+2$ $\left(\overline{\mathrm{X}}-\frac{\mathrm{g}}{2}\right) \cdot\left[\operatorname{arctg} \frac{\overline{\mathrm{X}}-\mathrm{g} / 2}{\mathrm{~d}}-\operatorname{arctg} \frac{\overline{\mathrm{X}}-\mathrm{g} / 2}{\mathrm{~d}+\delta}\right]-2(\overline{\mathrm{x}}+$ $\left.\left.\frac{\mathrm{g}}{2}\right) \cdot\left[\operatorname{arctg} \frac{\overline{\mathrm{X}}+\mathrm{g} / 2}{\mathrm{~d}}-\operatorname{arctg} \frac{\overline{\mathrm{x}}+\mathrm{g} / 2}{\mathrm{~d}+\delta}\right]\right\}$

$\mathrm{e}_{\mathrm{I}}(\overline{\mathrm{X}})=\frac{\alpha N \mathrm{NWM}_{\mathrm{r}} \mathrm{I}_{\mathrm{r}}\left(\mu-\mu_{0}\right)}{2 \pi\left(\mu+\mu_{0}\right)}\{(\mathrm{d}+\delta) \cdot \ln$ $\frac{(\overline{\mathrm{X}}-\mathrm{g} / 2)^{2}+(\mathrm{d}+\delta)^{2}}{(\overline{\mathrm{X}}+\mathrm{g} / 2)^{2}+(\mathrm{d}+\delta)^{2}}-(\mathrm{d}+2 \delta) . \quad \ln$ $\frac{(\overline{\mathrm{X}}-\mathrm{g} / 2)^{2}+(\mathrm{d}+2 \delta)^{2}}{(\overline{\mathrm{X}}+\mathrm{g} / 2)^{2}+(\mathrm{d}+2 \delta)^{2}}-2\left(\overline{\mathrm{X}}+\frac{\mathrm{g}}{2}\right) \cdot[\operatorname{arctg}$ $\left.\frac{\bar{X}+g / 2}{\mathrm{~d}+2 \delta}-\operatorname{arctg} \frac{\overline{\mathrm{X}}+\mathrm{g} / 2}{\mathrm{~d}+\delta}\right]+2\left(\overline{\mathrm{X}}-\frac{\mathrm{g}}{2}\right)[\operatorname{arctg}$ $\left.\left.\frac{\overline{\mathrm{X}}-\mathrm{g} / 2}{\mathrm{~d}+2 \delta}-\operatorname{arctg} \frac{\overline{\mathrm{X}}-\mathrm{g} / 2}{\mathrm{~d}+\delta}\right]\right\}$

$e_{R}(\bar{X})$ in (9) is the readback voltage of single -layer-medium for an isolated step perpendicular magnetization with a ring - type head. $e_{1}(\bar{X})$ in (10) is the increase part resulted from the presence of soft magnetic underlayer.

The readback waveforms for $\mu=2000$ or $\mu=$ 4000 are shown in Fig. 2 respectively.

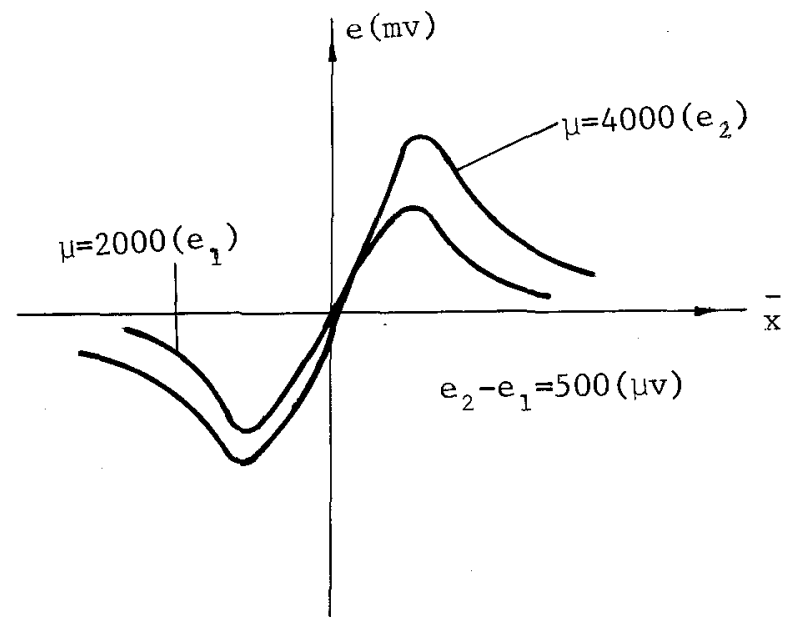

Figure 2. Readback waveforms for $\mu=2000$ and $\mu=4000$.
According to Fig. 2, the readback voltage is an increasing function of permeability $\mu$.

If the permeability of the ring - type head core is infinite, ( 8 ) becomes:

$$
\begin{gathered}
\mathrm{e}(\overline{\mathrm{X}})=\frac{\alpha N V W M_{\mathrm{r}} \mathrm{I}_{\mathrm{r}} \mathrm{g}}{2 \pi}\left\{\frac{(\mathrm{d}+2 \delta)}{\mathrm{g}} \cdot \ln \right. \\
\frac{\left.(\overline{\mathrm{X}} / \mathrm{g}+1 / 2)^{2}+(\mathrm{d}+2 \delta) / \mathrm{g}\right)^{2}}{\left.(\overline{\mathrm{X}} / \mathrm{g}-1 / 2)^{2}+(\mathrm{d}+2 \delta) / \mathrm{g}\right)^{2}}-\frac{\mathrm{d}}{\mathrm{g}} \ln
\end{gathered}
$$$$
\frac{(\overline{\mathrm{X}} / \mathrm{g}+1 / 2)^{2}+(\mathrm{d} / \mathrm{g})^{2}}{(\overline{\mathrm{X}} / \mathrm{g}-1 / 2)^{2}+(\mathrm{d} / \mathrm{g})^{2}}-2(\overline{\mathrm{X}} / \mathrm{g}+1 / 2) \cdot[\operatorname{arctg}
$$$$
\left.\frac{\bar{X} / \mathrm{g}+1 / 2}{(\mathrm{~d}+2 \delta) / \mathrm{g}}-\operatorname{arctg} \frac{\overline{\mathrm{X}} / \mathrm{g}+1 / 2}{\mathrm{~d} / \mathrm{g}}\right]+2\left(\frac{\overline{\mathrm{X}}}{\mathrm{g}}-\frac{1}{2}\right) \cdot
$$$$
\left.\left[\operatorname{arctg} \frac{\overline{\mathrm{X}} / \mathrm{g}-1 / 2}{(\mathrm{~d}+2 \delta) / \mathrm{g}}-\operatorname{arctg} \frac{\overline{\mathrm{X}} / \mathrm{g}-1 / 2}{\mathrm{~d} / \mathrm{g}}\right]\right\}=\mathrm{K} \cdot \theta(\overline{\mathrm{X}} \text {, }
$$
$\mathrm{g}, \mathrm{d}, \delta)$

\section{Where

$$
\mathrm{K}=\frac{\alpha N V W M_{\mathrm{r}} \mathrm{I}_{\mathrm{r}} \mathrm{g}}{2 \pi}
$$

$\mathrm{e}(\overline{\mathrm{X}})$ in $(11)$ is the readback voltage of an isolated step perpendicular magnetization for double-layer-medium with a ring - type head.

$$
e_{R}(\bar{X}), e_{\mathbf{x}}(\bar{X}), e(\bar{X}) \text { are all shown in Fig. } 3 .
$$

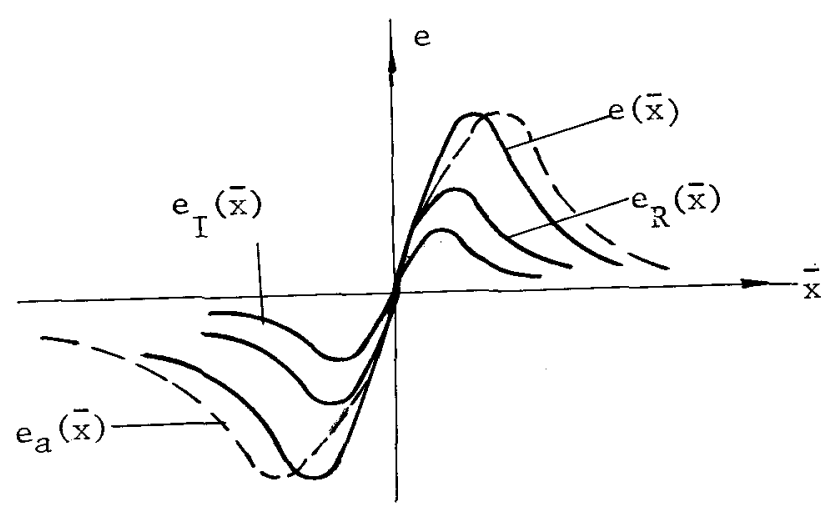

Figure 3. Readback waveform of an isolated perpendicular magnetization.

In the above analyses, the recording bit length is assumed to be infinite. If the recording bit length is $2 \mathrm{~L}$, the readback voltage $\theta_{\max }$ as a function of $\mathrm{L}$ is shown in Fig. 4. 


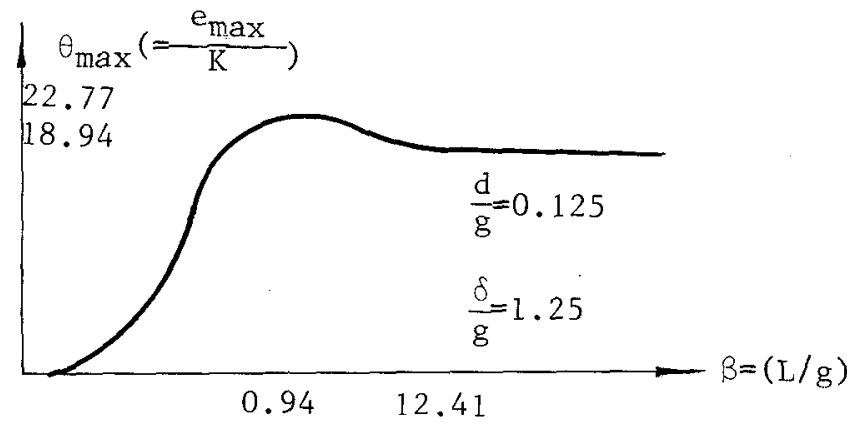

Figure 4. Readback voltage $\theta_{\max }$ as a function of $\mathrm{L}$.

CALCULATION OF READBACK VOLTAGE FOR AN ISOLATED ARCTANGENT PERPENDICULAR MAGNETIZATION

It is assumed that the magnetization follows the function:

$$
\left\{\begin{array}{l}
M_{x}(x, y, z)=0 \\
M_{y}(x, y, z)=\frac{2 M_{r}}{\pi} \operatorname{arctg} \frac{x_{0}-\bar{X}}{a} \\
M_{z}(x, y, z)=0
\end{array}\right.
$$

The total flux which enters the coils of the ring-type head is :

$$
\varphi(\bar{X})=\mu_{0} W \int_{d=y_{0}}^{d+\delta} d_{0} \int_{-\infty}^{\infty} \frac{2 M_{x}}{\pi} \operatorname{arctg} \frac{X_{0}-\bar{X}}{a} .
$$
$\mathrm{H}_{\mathrm{y}} \mathrm{dx}_{0}$

The readback voltage is $e(\overline{\mathrm{X}})$ in (7). Substituting (13) for $\varphi(\bar{X})$ in (7) and substituting (4) for $H_{y}$ in (13) give:

$$
\mathrm{e}_{\mathrm{a}}(\overline{\mathrm{X}})=\mathrm{e}_{\mathrm{Ra}}(\overline{\mathrm{X}})+\mathrm{e}_{\mathrm{ln}}(\overline{\mathrm{X}})
$$

If the permeability of the ring - type head is infinite, $e(\overline{\mathrm{X}})$ in (14) becomes:

$$
e_{a}(\bar{X})=\frac{\alpha N V W M_{r} I_{r}}{2 \pi}\{(d+a+2 \delta) \cdot \ln
$$

$\frac{(\bar{X}+g / 2)^{2}+(d+a+2 \delta)^{2}}{(\bar{X}-g / 2)^{2}+(d+a+2 \delta)^{2}}-(d+a) \cdot \ln$ $\frac{(\bar{X}+g / 2)^{2}+(d+a)^{2}}{(\bar{X}-g / 2)^{2}+(d+a)^{2}}-2(\bar{X}+g / 2) \cdot[\operatorname{arctg}$ $\left.\frac{\overline{\mathrm{X}}+\mathrm{g} / 2}{\mathrm{~d}+\mathrm{a}+2 \delta}-\operatorname{arctg} \frac{\overline{\mathrm{X}}+\mathrm{g} / 2}{(\mathrm{~d}+\mathrm{a})}\right]+2\left(\overline{\mathrm{X}}-\frac{\mathrm{g}}{2}\right) \cdot[\operatorname{arctg}$ $\left.\left.\frac{\bar{X}-\mathrm{g} / 2}{\mathrm{~d}+\mathrm{a}+2 \delta}-\operatorname{arctg} \frac{\overline{\mathrm{X}}-\mathrm{g} / 2}{\mathrm{~d}+\mathrm{a}}\right]\right\}$

$\mathrm{e}_{\mathrm{a}}(\overline{\mathrm{X}})$ in (15) is the readback voltage of an isolated arctangent perpendicular magnetization for double - layer - medium with a ring - type head. $\mathrm{e}_{\mathrm{a}}(\overline{\mathrm{X}})$ is shown in Fig. 3 (dashed Curve). If the arctangent transition parameter $a$ is very small, $e_{a}$ $(\overline{\mathrm{X}})$ in $(15)$ will becomes $\mathrm{e}(\overline{\mathrm{X}})$ in $(11)$.

\section{CONCLUTION}

The magnetic field component of a ring - type head for double-layer-medium in the presence of soft magnetic underlayer is calculated. The magnetic field is stronger than that for the single-layer - medium. The increase part of the magnetic field is $\mathrm{H}_{\mathrm{y} 1}$ in (3). For an isolated step transition in vertical magnetization, the calculated fields are used to compute the voltage induced on the read coil. On the basis of superposition principle, the readback voltage is stronger than that for the single-layer-medium. The increase part is $\mathrm{e}_{\mathrm{I}}(\overline{\mathrm{X}})$ in (10). According to the readback voltage formula, the readback voltage is an increasing function of permeability $\mu$. If the recording bit length is $2 \mathrm{~L}$, the readback voltage $\theta_{\text {rax }}$ versus $\beta=\mathrm{L} / \mathrm{g}$ is shown in Fig. 4. When $\beta$ is assumed to be 0.94 , the readback voltage $\theta_{\max }$ achieve the maximum. When $\beta \geqslant 12.41$, the readback voltage $\theta_{\max }$ tends to be steady and approach that of the condition in which 
the recording bit length is infinite. The readback voltage of an isolated arctangent perpendicular magmetization is also calculated. The result is $e_{a}$ $(\overline{\mathrm{X}})$ in $(14)$. The width for $\mathrm{e}(\overline{\mathrm{X}})$ is $90 \%$ of that for $e_{a}(\bar{X})$.

\section{REFERENCES}

[1] S. Iwasaki, "Perpendicular Magnetic Recording,"IEEE Trans. Magn., Vol. MAG16, No. 1 , 1980 PP71-76.

[2]S. Iwasaki, Y. NaKamura, K, ouchi,
"Perpendicular Magnetic Recording with a Composite Anisotropy Film," IEEE Trans. Magn., VoL. MAG-15, No. 6, 1979, PP1456-1458.

[3]K. Yamamori, R. Nishikawa, T. Asano and T. Fujiwara, "Perpendicular Magnetic Recording Performance of Double - layer Media," IEEE Trans. Magn., VoL. MAG-17, No. 6, 1981 PP2538-2540.

[4] Richard E. Matick, Computer Storage Systems and Technology, John Wiley and Sans, America, 1977. 